\title{
Fragmentação da vegetação da bacia hidrográfica do Rio Marapanim, nordeste do Pará
}

\author{
Vegetation fragmentation of Marapanim River watershed, northeastern of Pará \\ state
}

\begin{abstract}
Ádanna de Souza Andrade ${ }^{\mathrm{I}}$, Suezilde da Conceição Amaral RibeiroII, Bruno Wendell de Freitas Pereira ${ }^{\mathrm{III}}$, Valter Vinicius Pereira Brandão ${ }^{\text {iv }}$
\end{abstract}

\begin{abstract}
Resumo
A fragmentação florestal é uma das principais consequências das atividades antrópicas em áreas de vegetação nativa. Quando considerada a abordagem de bacias hidrográficas, a fragmentação pode aumentar processos erosivos e alterar o regime hídrico, notadamente em decorrência das ações de desmatamento. Assim, no presente estudo buscou-se analisar a estrutura da paisagem da bacia hidrográfica do rio Marapanim-PA, com o enfoque na fragmentação da vegetação arbórea. Para isso, foi utilizada uma cena do satélite Landsat 8, sensor OLI, adquirida em 2017 e classificada usando o algoritmo da Máxima Verossimilhança a fim de classificar e estimar os diferentes usos e coberturas da terra em 2017 na área da bacia. Subsequentemente, realizou-se a análise dos fragmentos florestais utilizando as métricas da paisagem em nível de mancha (patch), classe (class) e paisagem (landscape). Os resultados indicam que a paisagem da bacia hidrográfica é majoritariamente composta por vegetação arbórea (49\%) e áreas de agricultura (29\%), responsável pelas principais alterações na cobertura vegetal nativa da bacia estudada. O estudo da quantificação e caracterização da estrutura da paisagem mostrou que a paisagem da bacia se encontra muito fragmentada, com um total de 16.697 fragmentos. O tamanho médio dos fragmentos é de 12,79 ha, considerado de valor mediano para conservação da biodiversidade. A classe de vegetação arbórea éa mais fragmentada, representando $41,36 \%$ do total de fragmentos da paisagem da bacia. O índice de forma desses fragmentos é de 1,56, indicando a predominância de formas mais irregulares e, portanto, mais susceptível aos efeitos de borda. Os resultados deste estudo podem subsidiar a formulação de ações e/ou políticas públicas visando promover a recuperação e manutenção dos fragmentos da vegetação arbórea da bacia hidrográfica do rio Marapanim no estado do Pará.
\end{abstract}

Palavras-chave: Fragmentos florestais; Biodiversidade; Efeito de borda

\begin{abstract}
Forest fragmentation is one of the main consequences of anthropogenic activities in native vegetation areas. When considering the watershed approach, the fragmentation can increase the erosion processes and alter the water regime, notably as a result of deforestation actions. Thus, the present study sought to analyze the landscape structure of Marapanim river watershed, focusing on the fragmentation of tree vegetation. To do so, a Landsat 8, OLI sensor satellite scene acquired in 2017 and classified using the Maximum Likelihood algorithm was used to classify and estimate the different land uses and land cover in 2017 in the basin area. Subsequently, the forest fragments were analyzed using patch level, class and landscape metrics. The results indicate that the landscape of the watershed is mostly composed of tree vegetation (49\%) and agricultural areas (29\%), responsible for the main changes in the native vegetation cover of the studied basin. The study of the quantification and characterization of the landscape structure showed that the basin landscape is very fragmented, with a total of 16,697 fragments. The average fragment size is $12.79 \mathrm{ha}$, considered of medium value for biodiversity conservation. The class of tree vegetation is the most fragmented, representing $41.36 \%$ of the total fragments of the basin landscape. The shape index of these fragments is 1.56, indicating the predominance of more irregular shapes and therefore more susceptible to edge effects. The results of this study may support the formulation of actions and/or public policies aimed at promoting the recovery and maintenance of tree vegetation fragments of the Marapanim river watershed in the state of Pará.
\end{abstract}

Keywords: Forest fragments; Biodiversity; Edge effect

\footnotetext{
I Engenheira Ambiental e de Energias Renováveis, MSc., Professora do Departamento de Ensino, Instituto Federal do Pará - Campus Itaituba, Rua Universitário, s/n, Bairro Maria Magdalena, CEP 68183-300, Itaituba (PA), Brasil. adanna.souza@ifpa.edu.br (ORCID: 0000-0002-7516-3862)

Engenheira Química, Drạ., Colegiado do Programa de Pós-Graduação em Ciências Ambientais, Universidade do Estado do Pará, Travessa Enéas Pinheiro, 2625, Bairro Marco, CEP 66095-015, Belém (PA), Brasil. suziar@yahoo.com.br (ORCID: 000-0002-1661-7609)

III Engenheiro agrônomo, Dr., Professor do Instituto Ciber Espacial, Universidade Federal Rural da Amazônia, Avenida Presidente Tancredo Neves, 2501, Bairro Terra Firme, CEP 66.077-830, Belém (PA), Brasil. brunowendell@yahoo.com.br (ORCID: 0000-0002-3823-6292)

IV Licenciado em Geografia, Especialista, Professor da Secretaria de Estado de Educação, Tv. Dezessete de outubro, s/n, Bairro Pajuçara, CEP 68220000, Monte Alegre (PA), Brasil. viniciuspgeo@gmail.com (ORCID: 0000-0003-0924-2885)
} 


\section{Introdução}

Uma das principais consequências das ações antrópicas visando o uso do solo em áreas de vegetação é o processo de fragmentação florestal, o qual é caracterizado pela ruptura da unidade da paisagem, formando pequenos fragmentos florestais isolados onde anteriormente existia área de floresta contínua. Isso gera a separação florestal e provoca o isolamento entre as espécies, contribuindo assim para a perda da biodiversidade e extinção dessas espécies (LAURANCE et al., 2001).

Os impactos decorrentes dessa ruptura envolvem a formação de paisagens com pouca diversidade de habitats, presença de fragmentos isolados geograficamente e de dimensões reduzidas, além do aumento nos efeitos de borda, alterações nas interações ecológicas das espécies, aumento das relações de predação e competição e perda de micro-hábitat das espécies (PIROVANI et al., 2014).

A paisagem é definida por Bertrand (2004) como resultado da combinação dinâmica de elementos físicos, biológicos e antrópicos, e, portanto, está em constante evolução. Assim, a paisagem não se limita ao "natural", mas sim a uma paisagem total, que integra as implicações da ação antrópica. Nesse sentido, a paisagem da região Amazônica vem sendo alterada significativamente ao longo do seu processo de ocupação, o que pode causar fortes desequilíbrios socioambientais (SOUZA et al., 2011). A bacia hidrográfica é um elemento da paisagem e é considerada uma das áreas que mais vêm sofrendo as alterações decorrentes de ações antrópicas.

A bacia hidrográfica do rio Marapanim está inserida na mesorregião do nordeste do estado do Pará, a qual é a mais antiga em colonização da Amazônia e, portanto, possui uma paisagem antropizada com grande parte da vegetação nativa fragmentada (VIEIRA; TOLEDO; ALMEIDA, 2007).

Azevedo, Gomes e Moraes (2016) destacaram que a fragmentação dos remanescentes florestais no âmbito da bacia hidrográfica leva à diminuição da qualidade ambiental, notadamente pela intensificação dos processos erosivos ocasionada pelas ações de desmatamento e falta de cobertura vegetal adequada. Além disso, Hentz et al. (2015) explicaram que quando o processo de fragmentação florestal é principalmente impulsionado por atividades antrópicas, prejudica a conservação da biodiversidade, pois provoca extinções locais, redução da área de habitat, acentuação do efeito de borda, redução da variabilidade genética, além de alteração no regime hídrico de bacias hidrográfica.

Assim, o estudo da estrutura da paisagem e o padrão espacial dos fragmentos são de fundamental importância, a fim de se estabelecer estratégias de conservação. Nesse sentido, a ecologia das paisagens vem sendo utilizada em tais estudos, já que permite analisar as interações espaciais entre as unidades naturais e culturais da paisagem, assim como compreender de que forma os padrões espaciais da paisagem influenciam nos processos ecológicos (METZGER, 2001).

A estrutura da paisagem é composta pelos seguintes elementos: matriz, manchas e corredores. A matriz representa a cobertura de fundo da paisagem, apresentando-se com maior conectividade e com papel dominante no funcionamento da paisagem, exercendo influência sobre os demais elementos. As manchas (ou fragmentos) são áreas relativamente homogêneas que diferem das demais ao seu redor e variam em tamanho, forma, tipo e características de borda, influenciando nas relações ecológicas. Os corredores são estruturas lineares da paisagem com características diferentes das manchas e que possuem a função de ligar dois ou mais fragmentos anteriormente unidos (CASIMIRO, 2009).

O geoprocessamento tem sido uma ferramenta eficaz na caracterização da estrutura da paisagem e compreensão dos efeitos da fragmentação florestal em bacias hidrográficas, municípios e unidades de conservação, o que possibilita o diagnóstico das condições dos fragmentos em termos, por exemplo, de diversidade, tamanho e grau de isolamento, facilitando, assim, a aplicação de medidas de recuperação em áreas fragmentadas (CALEGARI et al., 2010).

A análise do padrão de fragmentação pode ser feita por meio das métricas da paisagem, 
métricas de classe e métricas do fragmento por classe de tamanho, os quais permitem compreender a complexa estrutura da paisagem e as influências nas relações ecológicas, bem como acompanhar a dinâmica de evolução das unidades de paisagem devido ao processo de fragmentação em decorrência do uso sem planejamento do território (JUVANHOL et al., 2011).

Assim, o presente estudo inclui a análise da distribuição espacial dos fragmentos de vegetação arbórea da bacia hidrográfica do rio Marapanim-PA, possibilitando definir estratégias de conservação da biodiversidade. Nesse sentido, o objetivo desta pesquisa foi analisar a estrutura da paisagem e os fragmentos florestais da vegetação arbórea da bacia hidrográfica do rio Marapanim, localizada no nordeste do Pará, utilizando dados de sensoriamento remoto e técnicas de geoprocessamento.

\section{Material e método}

\section{Área de estudo}

A Bacia Hidrográfica do rio Marapanim (Figura 1) possui uma área de $2.141 .26 \mathrm{~km}^{2} \mathrm{e}$ está inserida na mesorregião do nordeste paraense, localizada entre as coordenadas geográficas $0^{\circ} 32^{\prime} 19.075^{\prime \prime}$ e $1^{\circ} 18^{\prime} 36.961^{\prime}$ 'S e $47^{\circ} 31^{\prime} 45.232$ ” e 48²'20.954”W. Esta bacia está inserida parcialmente em 12 municípios paraenses: Castanhal, Curuçá, Terra Alta, São Francisco, IgarapéAçu, Maracanã, Magalhães Barata, Santa Izabel do Pará, Santo Antônio do Tauá, São Caetano, Vigia de Nazaré e Marapanim.

\section{Figura 1 - Localização da Bacia Hidrográfica do rio Marapanim no estado do Pará}

Figure 1 - Spatial location of Marapanim river watershed in the state of Para, Brazil

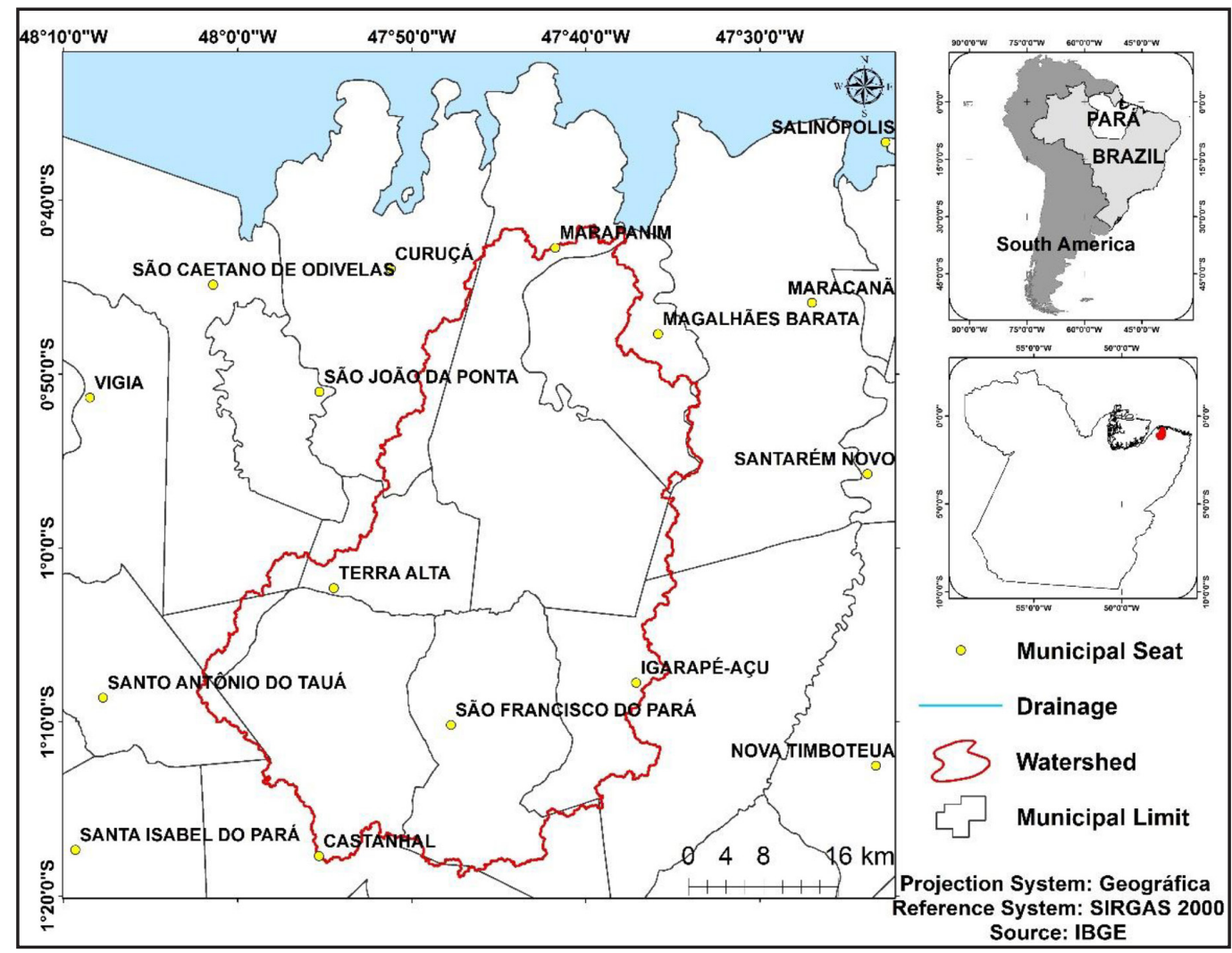

Fonte: Autores (2019) 
O Clima na área de estudo é do tipo "Am”, de acordo com a classificação de Köppen, subdividido em Am2, com precipitação pluviométrica média anual variando entre $2500 \mathrm{~mm}$ e $3000 \mathrm{~mm}$ e temperatura média anual em torno de 26,5ํㅡ (ALVARES et al., 2014).

\section{Obtenção e processamento digital de imagem}

Uma imagem digital orbital obtida pelo sensor OLI (Operational Land Imager) a bordo do satélite Landsat-8 foi utilizada para a classificação do uso e cobertura da terra na área de estudo. A imagem corresponde à órbita ponto 223/61, bandas 4, 5 e 6, correspondente ao dia 06/07/2017, adquirida no sítio da internet da Agência Americana National Aeronautics and Space Administration (NASA) e reprojetada para o hemisfério Sul. O software utilizado no processamento da imagem foi o Environment For Visualizing Images, ENVI 5.2.

A imagem foi corrigida atmosfericamente utilizando o método DOS (Dark Object Subtration) proposto por Chavez (1988), para reduzir os efeitos atmosféricos da radiação refletida. Assim, a interferência atmosférica, nesse método, é estimada a partir dos Números Digitais (ND) das imagens de satélite, sendo ignorada a absorção atmosférica. No método DOS, cerca de 1\% da reflectância é ocasionada por pixels escuros nas imagens, que deveriam apresentar valores baixos de ND, tais como sombras e nuvens. Entretanto, em virtude do espalhamento atmosférico, esses pixels possuem valores acima do esperado na imagem e, dessa forma, servem de parâmetro para a correção atmosférica. Nesse sentido, para a realização da correção atmosférica, a banda B1 foi escolhida e, a partir do valor de um pixel escuro, foi estimado o valor do espalhamento por banda espectral. A correção é realizada pela subtração dos valores estimados para toda a imagem.

\section{Trabalhos de campo}

Os trabalhos realizados no campo compreenderam o reconhecimento e caracterização da paisagem da área de estudo, com o objetivo de correlacionar as classes temáticas definidas a partir da interpretação das imagens com os padrões de cobertura vegetal observados no campo. Foram realizadas visitas de campo no período de 12 a 23 de junho de 2017 quando foram feitos registros fotográficos da área e coleta de pontos de controle em cada feição presente na bacia, com auxílio de GPS de navegação (Garmin 62sc). Em cada feição da paisagem, foram coletados 10 pontos de controle, os quais serviram de suporte para gerar a classificação supervisionada da imagem de satélite. Assim, o trabalho de campo identificou as seguintes feições: corpos de água, vegetação nativa, vegetação secundária, solo exposto, agricultura e áreas alteradas.

\section{Classificação supervisionada da imagem}

A classificação de imagens digitais é utilizada para identificação dos alvos, fenômenos ou feições que apresentam padrões espectrais similares, de modo a permitir atribuí-los a uma determinada classe. A identificação das áreas amostrais de cada classe foi baseada em uma composição falsa cor R6G5B4 a partir de um recorte vetorial da bacia hidrográfica. As classes utilizadas no processo de classificação digital foram: vegetação arbórea, representada tanto pela vegetação nativa quanto pela secundária; solo exposto e área urbana; agricultura; corpos de água; e áreas alteradas. A última classe representou as áreas degradadas pelo uso intensivo do solo.

Neste trabalho, o processo de classificação foi realizado pelo algoritmo de Máximaverossimilhança (Maxrver), um método de classificação supervisionada, que considera a ponderação das distâncias entre as médias dos valores dos pixels das classes, a partir de parâmetros estatísticos.

O classificador Maxrver assume que todas as bandas possuem distribuição normal e calcula a probabilidade de um pixel pertencer a uma determinada classe. Esse método é subsidiado com base em uma noção prévia, adquirida a partir de áreas amostrais representativas de cada classe de interesse. Esse 
conhecimento prévio é obtido por meio das informações das classes que integram a área de estudo e podem ser representadas por áreas amostrais.

Posteriormente, foi realizada a classificação do restante da imagem, a partir das áreas amostrais e das regras estatísticas já estabelecidas. A classificação foi efetuada levando em consideração as informações espectrais visualmente observadas utilizando a composição colorida R6G5B4 das bandas de refletância 4,5 e 6 do Landsat 8.

Após a classificação, foi feita a edição visual de pixels classificados erroneamente utilizando a ferramenta ClassEdit disponível no software ENVI 5.2. Com o objetivo de reduzir a quantidade de pixels isolados e assim aumentar a uniformidade das classes definidas, aplicou-se o filtro majoritário, através de uma máscara de dimensão 3x3.

No intuito de verificar o desempenho da classificação digital aplicada, foram analisadas as matrizes de confusão, bem como o índice de exatidão Kappa, o qual foi obtido 0,9363 para a imagem,sendo a qualidade da classificação considerada excelente.

\section{Análise dos fragmentos florestais}

A configuração da paisagem e dos fragmentos de vegetação remanescente foram analisados utilizando o software ArcGIS ${ }^{\circledR}$, pela extensão Patch Analyst. Essa ferramenta é frequentemente utilizada para análises do padrão espacial, como suporte para o estudo da conservação da biodiversidade e manejo florestal, uma vez que calcula diversas métricas em nível de mancha (patch), classe (class) e paisagem (landscape). Além disso, possibilita a análise de inúmeras métricas para quantificar a composição e/ou a configuração da paisagem, que afetam de forma significativa os processos ecológicos na bacia hidrográfica do rio Marapanim.

As métricas referentes aos fragmentos da paisagem e de vegetação arbórea geradas no presente estudo estão descritas na Tabela 1. Tais métricas permitem quantificar e descrever os padrões espaciais da paisagem a partir dos aspectos de composição (presença e número de fragmentos existentes) e configuração (distribuição física e características espaciais - forma, área central, proximidade, conectividade, dentre outras) (MCGARIGAL; MARKS, 1995).

\section{Tabela 1 - Descrição das métricas analisadas no estudo}

Table 1 - Description of the metrics analyzed in the study

\begin{tabular}{cc}
\hline Métrica \\
\hline Área total \\
Número de fragmentos \\
& Tamanho médio dos fragmentos \\
$\begin{array}{l}\text { Métricas da } \\
\text { paisagem }\end{array}$ & Índice de diversidade de Shannon
\end{tabular}

\footnotetext{
O índice será igual a zero, quando há apenas mancha de uma única classe na paisagem e aumenta conforme o número de classes de manchas na paisagem, ou distribuição proporcional das diferentes classes de manchas na paisagem.
}

Índice de uniformidade de Shannon
Ele é igual a 1 quando a distribuição de área entre manchas é exatamente a mesma, e tende a 0 quando a distribuição de espaço entre as manchas torna-se cada vez mais dominado por uma classe de mancha (HOLANDA et al., 2010). 
Tabela 1 - Conclusão ...

Table 1 - Conclusion ...

\begin{tabular}{|c|c|c|}
\hline & Métrica & Descrição \\
\hline \multirow{2}{*}{$\begin{array}{l}\text { Métricas da } \\
\text { paisagem }\end{array}$} & Índice de Contágio & $\begin{array}{l}\text { Avalia o contágio (adjacência) dos pixels sobre a possibilidade } \\
\text { máxima de contágio para o número de classes da paisagem. }\end{array}$ \\
\hline & $\begin{array}{l}\text { Índice de intercalação e } \\
\text { justaposição }\end{array}$ & $\begin{array}{c}\text { É a intercalação observada sobre a máxima intercalação } \\
\text { possível para um dado número de tipos de classes. }\end{array}$ \\
\hline \multirow{8}{*}{$\begin{array}{l}\text { Métricas } \\
\text { de } \\
\text { classe }\end{array}$} & Área total & $\begin{array}{l}\text { Soma das áreas de todos os fragmentos que compõem a } \\
\text { vegetação remanescente da área de estudo. }\end{array}$ \\
\hline & Número de fragmentos & $\begin{array}{l}\text { Soma do número total de fragmentos que compõem a } \\
\text { vegetação arbórea da área de estudo. }\end{array}$ \\
\hline & Tamanho médio dos fragmentos & $\begin{array}{l}\text { Soma do número total de fragmentos que compõem a } \\
\text { vegetação arbórea da área de estudo dividido pela sua área. }\end{array}$ \\
\hline & Comprimento total de borda & $\begin{array}{c}\text { Soma dos perímetros de todos os fragmentos que compõem a } \\
\text { vegetação arbórea da área de estudo. }\end{array}$ \\
\hline & Dimensão fractal média & $\begin{array}{c}\text { Mede a complexidade da forma dos fragmentos que compõem } \\
\text { a vegetação arbórea da área de estudo. Varia de } 1 \text { (para } \\
\text { manchas com formas mais simples e regulares) a } 2 \text { (para } \\
\text { manchas com formas mais complexas). }\end{array}$ \\
\hline & Percentual de área central & $\begin{array}{c}\text { Percentual de áreas centrais (excluídas as bordas) em relação à } \\
\text { área total da paisagem. }\end{array}$ \\
\hline & Índice de proximidade médio & $\begin{array}{c}\text { Distância média entre fragmentos da classe, com base em um } \\
\text { raio previamente determinado. }\end{array}$ \\
\hline & Índice de conectividade & $\begin{array}{l}\text { Valores de conectividade próximos de zero indicam que } \\
\text { a classe está subdividida e menos conectada fisicamente, } \\
\text { enquanto valores próximos de } 100 \% \text { indicam maior agregação } \\
\text { e, portanto, menos isolamento dos fragmentos da classe } \\
\text { (MCGARIGAL; MARKS, 1995). }\end{array}$ \\
\hline
\end{tabular}

Métricas de Número de fragmentos frragmento agrupados para cada classe
Número de fragmentos em cada classe de tamanho.

Fonte: Autores (2019)

\section{Resultados e discussão}

A caracterização do uso e cobertura da terra da bacia hidrográfica do rio Marapanim no estado do Pará incluiu cinco feições distintas: vegetação arbórea, água, solo exposto e área urbana, agricultura e áreas alteradas. A classe de vegetação arbórea foi obtida a partir da união da classe de vegetação densa (nativa) e vegetação rasteira (secundária).

A matriz de confusão gerada a partir da classificação da imagem de satélite, juntamente com a acurácia e os erros por classes estão demonstradas na Tabela 2. Congalton (1991) enfatizou que a maneira mais comum de representar a precisão da classificação de dados de sensoriamento remoto é na forma de uma matriz de erros, a qual é considerada muito eficiente, pois as precisões 
de cada categoria são descritas claramente e, a partir da matriz de erros, pode-se obter a precisão geral, a qual é calculada dividindo-se o valor total da soma da diagonal principal pelo número total de pixels na matriz de erro. Assim, a precisão geral da classificação identificada a partir da matriz de erro (Tabela 2) é de 0,95.

Tabela 2 - Matriz de confusão gerada a partir da classificação da imagem de satélite

Table 2 - Confusion matrix generated from satellite image classification

\begin{tabular}{|c|c|c|c|c|c|c|c|}
\hline $\begin{array}{c}\text { Acurácia: } 94.90 \% \\
\text { Coeficiente } \\
\text { Kappa: } 0.93 \\
\text { Classes }\end{array}$ & $\begin{array}{c}\text { Vegetação } \\
\text { densa }\end{array}$ & Água & $\begin{array}{c}\text { Solo } \\
\text { exposto }\end{array}$ & Agricultura & $\begin{array}{l}\text { Vegetação } \\
\text { rasteira }\end{array}$ & $\begin{array}{c}\text { Áreas } \\
\text { alteradas }\end{array}$ & Total \\
\hline $\begin{array}{l}\text { Não } \\
\text { classificados }\end{array}$ & 0 & 0 & 0 & 0 & 0 & 0 & 0 \\
\hline Vegetação densa & 3653 & 2 & 0 & 2 & 158 & 7 & 3822 \\
\hline Água & 4 & 2253 & 0 & 0 & 6 & 0 & 2263 \\
\hline Solo exposto & 0 & 0 & 2364 & 8 & 0 & 0 & 2372 \\
\hline Agricultura & 0 & 0 & 0 & 3994 & 73 & 0 & 4067 \\
\hline $\begin{array}{l}\text { Vegetação } \\
\text { rasteira }\end{array}$ & 114 & 0 & 7 & 363 & 2653 & 82 & 3219 \\
\hline Áreas alteradas & 0 & 0 & 0 & 0 & 0 & 462 & 462 \\
\hline Total & 3771 & 2255 & 2371 & 4367 & 2890 & 551 & 16205 \\
\hline Classes & $\begin{array}{c}\text { Vegetação } \\
\text { densa }\end{array}$ & Água & $\begin{array}{c}\text { Solo } \\
\text { exposto } \\
\end{array}$ & Agricultura & $\begin{array}{c}\text { Vegetação } \\
\text { rasteira }\end{array}$ & $\begin{array}{c}\text { Áreas } \\
\text { alteradas }\end{array}$ & Total \\
\hline $\begin{array}{l}\text { Não } \\
\text { classificados }\end{array}$ & 0 & 0 & 0 & 0 & 0 & 0 & 0 \\
\hline Vegetação densa & 96.87 & 0.09 & 0 & 0.05 & 5.47 & 1.27 & 23.59 \\
\hline Água & 0.11 & 99.91 & 0 & 0 & 0.21 & 0 & 13.96 \\
\hline Solo exposto & 0 & 0 & 99.7 & 0.18 & 0 & 0 & 14.64 \\
\hline Agricultura & 0 & 0 & 0 & 91.46 & 2.53 & 0 & 25.1 \\
\hline $\begin{array}{l}\text { Vegetação } \\
\text { rasteira }\end{array}$ & 3.02 & 0 & 0.3 & 8.31 & 91.8 & 14.88 & 19.86 \\
\hline Áreas alteradas & 0 & 0 & 0 & 0 & 0 & 83.85 & 2.85 \\
\hline Total & 100 & 100 & 100 & 100 & 100 & 100 & 100 \\
\hline
\end{tabular}

Fonte: Autores (2019)

A classe dominante na paisagem da bacia deste estudo é a de vegetação arbórea, composta por florestas nativas e primárias ou em diferentes estágios de sucessão secundária. As áreas de sucessão secundária estão associadas às ocupações antrópicas, principalmente atividades pecuárias, características do nordeste paraense, ocupando $42 \%$ da área da bacia. As áreas de vegetação nativa e de vegetação secundária ocupam, juntas, $49,6 \%$ da área da bacia estudada (Tabela 3, Figura 2). 
Tabela 3 - Cobertura vegetal e uso do solo na bacia hidrográfica do rio Marapanim, estado do Pará

Table 3 - Land use and land cover in Marapanim river watershed, state of Pará

\begin{tabular}{lcc}
\hline \multicolumn{1}{c}{ Classes } & Área (ha) & Percentual (\%) \\
\hline Agricultura & $63.925,58$ & 29,85 \\
Corpos de Água & $5.880,22$ & 2,74 \\
Áreas alteradas & $6.971,62$ & 3,25 \\
Solo exposto e área urbana & $31.021,24$ & 14,48 \\
Vegetação arbórea & $106.327,75$ & 49,68 \\
\hline Total & $214.126,44$ & 100 \\
\hline
\end{tabular}

Fonte: Autores (2019)

Figura 2 - Uso e cobertura do solo na bacia hidrográfica do rio Marapanim em 2017

Figure 2 - Land use and land cover in Marapanim river watershed by 2017

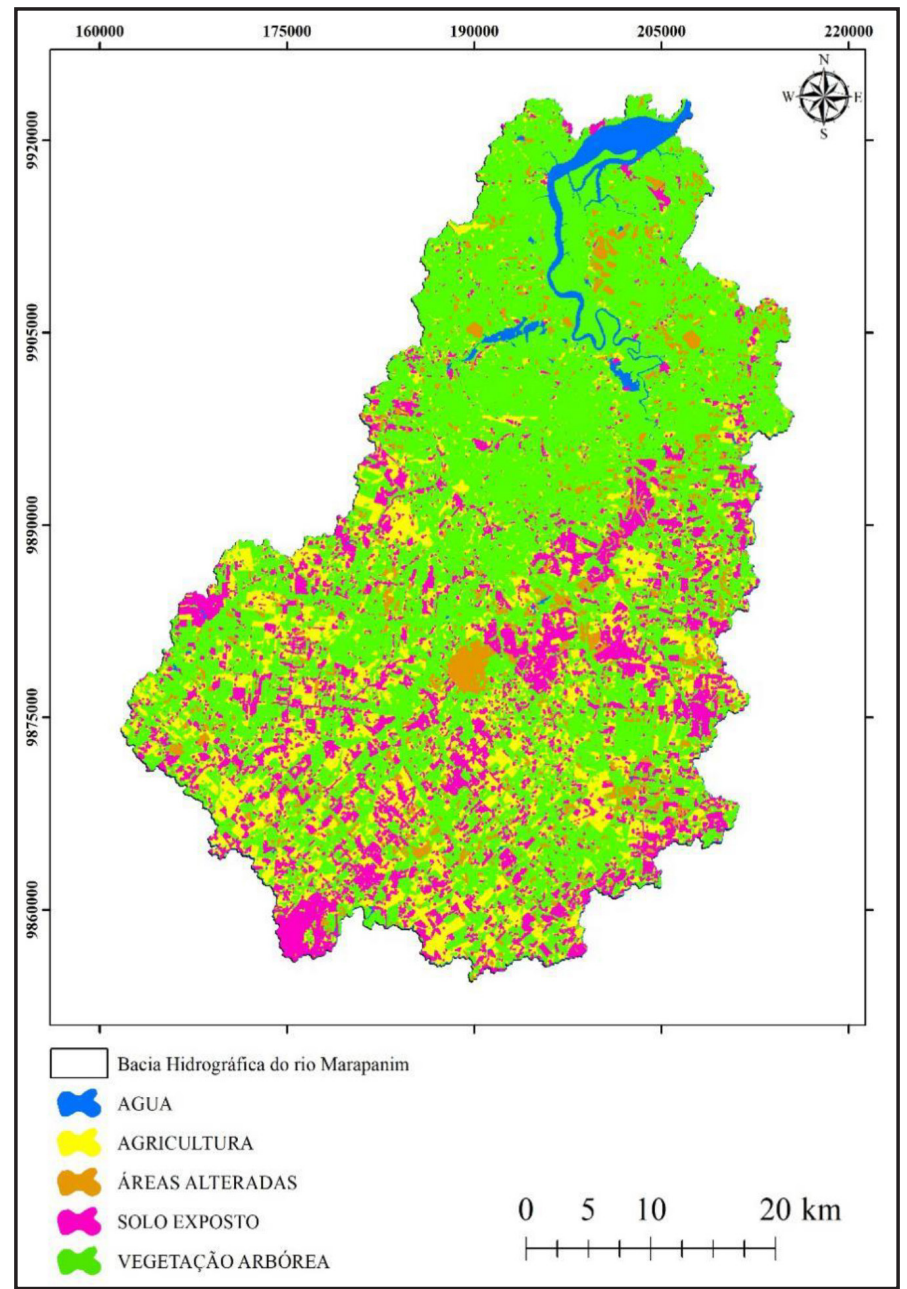

Fonte: Autores (2019) 
Outros estudos de bacias hidrográficas do nordeste paraense evidenciaram o significativo percentual de áreas de vegetação secundária, como o de Souza et al. (2011). Os autores constataram que as áreas de sucessão secundária ocupavam $30 \%$ da área da bacia hidrográfica do rio Apeú, nordeste paraense.

A agricultura ocupava $29,8 \%$ da área total da bacia estudada (Tabela 3 ). O nordeste paraense apresenta como base a agricultura de subsistência de base familiar, com práticas tradicionais como o sistema de corte e queima para o preparo da área (CORDEIRO; RANGELVASCONCELOS; SCHWARTZ, 2017).

Nesse sistema de corte e queima, as culturas são incorporadas nas áreas e perduram por um período de 3 a 4 anos, quando estas são abandonadas e ocupadas pela vegetação espontânea (pousio), até que o solo recupere sua fertilidade. Entretanto, devido à tendência de crescimento populacional e a necessidade de maior produção de alimentos, esse período de pousio vem diminuindo, assim como há maior intensificação do período agrícola, tornando, assim, o sistema insustentável (CORDEIRO; RANGEL-VASCONCELOS; SCHWARTZ, 2017).

As classes de solo exposto e área urbana ocuparam $14,4 \%$ da área bacia e representaram tanto as áreas de exposição do solo relacionadas ao sistema produtivo quanto as sedes urbanas dos doze municípios que compõe a bacia hidrográfica. Os corpos de água ocuparam $2,7 \%$ da bacia deste estudo, sendo representada pelo rio principal (Marapanim) e seus tributários, além das nascentes.

A análise da caracterização e quantificação espacial da paisagem, realizada a partir das métricas de paisagem, mostrou que a área total que compõe a bacia hidrográfica do rio Marapanim é de 214.126,44 ha. Um total de 16.697 fragmentos compunham a paisagem da área em 2017, o que a caracteriza uma paisagem muito fragmentada. De acordo com Arima et al. (2013), a fragmentação florestal altera a conectividade da floresta e seus padrões influenciam nos processos ecológicos e na perspectiva de sobrevivência das espécies, impactando o habitat animal, a biodiversidade, os processos de regeneração natural e a biomassa.

O tamanho médio dos fragmentos da paisagem é de 12,79 ha. Calegari et al. (2010) enfatizaram que o tamanho médio dos fragmentos também é um bom indicativo do grau de fragmentação da paisagem, sendo que quanto menor o tamanho médio desses fragmentos, mais fragmentada é a paisagem e menor é a capacidade de abrigar a diversidade biológica.

Laurance (1997) classificou o tamanho dos fragmentos de acordo com seu valor para a conservação da biodiversidade, de modo que fragmentos de alto valor apresentam medidas maiores que 300 ha, fragmentos com valor mediano apresentam entre 3 e 300 ha e fragmentos de baixo valor apresentam medidas menores que 3 ha. Com base nessa classificação proposta por Laurance (1997), com uma média de tamanho de 12,79 ha, os fragmentos de vegetação arbórea da bacia hidrográfica do rio Marapanim apresentam valor mediano de conservação da biodiversidade.

O índice de diversidade de Shannon da paisagem estimado para a área de estudo foi de 1,19 , o que indica baixa diversidade de usos na área da bacia, enfatizado pelo predomínio da classe de vegetação arbórea na paisagem da bacia hidrográfica. O índice de uniformidade estimado foi de 0,74 , indicando que os tipos de uso e ocupação não estão igualmente distribuídos na paisagem da bacia, ou seja, há dominância da classe de vegetação arbórea em relação às outras, enfatizando a complexidade mediana da paisagem (COELHO et al., 2014).

O índice de contágio, métrica que avalia o contágio (adjacência) dos pixels sobre a possibilidade máxima de contágio para o número de classes da paisagem, foi de 32,34\%. Valores baixos de contágio indicam que existem muitas manchas pequenas na paisagem, dessa forma essas manchas estão menos agregadas, o que afeta os processos ecológicos e organismos presentes na paisagem (PEREIRA et al., 2001). Além disso, Vidolin, Biondi e Wandembruck (2011) enfatizaram que o índice de contágio se relaciona diretamente ao grau de isolamento dos fragmentos na paisagem, já que permite avaliar a extensão na qual os fragmentos ou classes estão agregados ou dispersos na paisagem. Assim, um baixo índice de contágio indica um alto grau de isolamento das manchas na paisagem. 
O índice de intercalação e justaposição (IJI) refere-se ao nível de intercalação dos fragmentos e leva em consideração as classes dos fragmentos vizinhos. O valor obtido para a paisagem foi de $65,30 \%$, indicando assim bom nível de mistura entre os fragmentos das diferentes classes que se encontram relativamente bem distribuídos por toda a paisagem (REZENDE, 2011). De acordo com Pereira et al. (2001), a justaposição é primordial para organismos que requerem dois ou mais tipos de habitats, pois a sobrevivência e reprodução destes depende fundamentalmente da proximidade de recursos fornecidos por diferentes tipos de manchas.

A classe de vegetação arbórea é caracterizada como uma matriz da paisagem, ou seja, a classe mais abundante. Essa classe se apresenta bastante fragmentada, com um total de 6.906 fragmentos, representando $41,36 \%$ do total de fragmentos da paisagem da bacia. Essa alta fragmentação identificada na área enfatiza a ação antrópica como agente que acelera tal processo, notadamente a partir das atividades agropecuárias, comuns na região de estudo.

Os fragmentos da classe de vegetação arbórea apresentaram um tamanho médio de 15,39 ha, onde o maior fragmento possui $29.287,3$ ha e o menor fragmento 0,09 ha. Nascimento e Laurance (2006) associam o tamanho do fragmento com a susceptibilidade ao efeito de borda, destacando que quanto menor o fragmento, maior é a razão borda/área e consequentemente maior é o efeito de borda, tornando as espécies presentes nesses fragmentos mais sujeitas aos eventos extremos, além de reduzir a biodiversidade de espécies, visto o tamanho reduzido não possuir as características ambientais suficientes para abrigar a biodiversidade.

Apesar disso, deve-se ressaltar que os fragmentos de menor tamanho têm a sua importância na paisagem, haja vista funcionarem como elementos de ligação, ou "trampolins ecológicos” entre os fragmentos de grandes áreas (PIROVANI et al., 2014).

O comprimento total de borda dos fragmentos de vegetação arbórea foi de $13.416,39 \mathrm{~km}$, enfatizando assim o alto grau de fragmentação da vegetação da bacia, haja vista que quanto maior o comprimento de borda, maior a fragmentação. De acordo com Pirovani et al. (2014), a borda é sujeita a impactos oriundos da matriz antrópica que alteram a composição de espécies e a estrutura da vegetação.

Laurance et al. (2000) analisaram o efeito da fragmentação em árvores na Amazônia e constataram que árvores grandes $(\mathrm{DAP}>=60 \mathrm{~cm}$ ) tiveram mortalidade quase três vezes mais rápida quando estavam em menos de 300 metros de borda quando comparado ao interior da floresta. Essa mortalidade ocorre devido às mudanças repentinas ocasionadas pela criação de bordas, principalmente nas taxas de temperatura do ar, umidade do ar e do solo e aumento na velocidade dos ventos.

A densidade de borda, métrica que relaciona o comprimento total de borda de cada classe pela área total da paisagem, foi de $25,22 \mathrm{~m} / \mathrm{ha}$, sendo a maior densidade dentre todas as classes. A densidade de borda é tanto maior quanto maior for o número de fragmentos de uma classe, assim, um maior valor de densidade implica em maior fragmentação da paisagem (CALEGARI et al., 2010).

O índice de forma dos fragmentos da vegetação arbórea da área da bacia foi de 1,56, indicando fragmentos com forma mais irregular, já que quanto mais próximo de 1 , a forma do fragmento é mais parecida com um círculo. A forma tem influência direta na intensidade do efeito de borda que o fragmento está sujeito, ou seja, quanto mais próximo da forma circular, menor é a borda do fragmento, estando assim menos sujeito às perturbações externas. De acordo com Almeida (2008), o aumento de bordas expostas eleva a temperatura do ar e o déficit de pressão de vapor, podendo se estender para o interior dos fragmentos causando desequilíbrios nas relações ecológicas e comprometendo a existência das espécies de fauna e flora.

O percentual de área central (excluídas as bordas) em relação à área total da paisagem foi de 49,73\%, considerando um raio de 100 metros (CABACINHA; CASTRO; GONÇALVES, 2010). A área central expressa a relação entre a área disponível e a área realmente útil, já que determinados fragmentos possuem área suficiente para manter uma determinada espécie, porém não possuem área suficiente para permitir a manutenção da espécie (MACHADO et al., 2012). 
No que diz respeito à proximidade das manchas da classe de vegetação arbórea, esta foi avaliada a partir do índice de proximidade médio, calculado a partir de um raio de busca de 100 metros (DIAS et al., 2019). Para esse raio de busca, a proximidade obtida foi igual a zero. Cabacinha, Castro e Gonçalves (2010) mostraram que quando a proximidade é igual a zero, indica que a classe não possui vizinhos de mesmo tipo dentro do raio de busca especificado.

A conectividade dos fragmentos de vegetação arbórea da bacia foi de 0,40 , considerada baixa. O isolamento entre fragmentos reflete o grau de dificuldade de deslocamento de determinadas espécies, e, consequentemente, a riqueza dessas espécies, já que fragmentos mais isolados dificultam a imigração e recolonização, o que influencia na sobrevivência de metapopulações (BENDER; THISCHENDORF; FAHRIG, 2003). Assim, a conectividade é fator primordial para a dinâmica populacional na paisagem, de modo que uma baixa conectividade limita a dispersão dos organismos e reduz o fluxo genético entre as populações, causando assim a perda de diversidade genética (MEDINA; VIEIRA, 2007). Uma das formas de mitigar a falta de conectividade na paisagem é pela incorporação de corredores ecológicos, os quais visam ligar dois ou mais fragmentos isolados, considerados uma alternativa para ampliação do fluxo gênico.

A subdivisão dos fragmentos por classe de tamanho mostrou que a maioria dos fragmentos da vegetação arbórea da bacia são menores que 50 hectares, correspondendo a $97,24 \%$ do total de fragmentos encontrados (6.906). Fragmentos pequenos reduzem a riqueza quanto menor for a área para sobrevivência das populações (JUVANHOL et al., 2011). Além disso, fragmentos menores possuem também menor densidade de espécies, ou seja, menor número de espécies por unidade de área, além de menor variedade de habitats, o que pode causar o desaparecimento de espécies dependentes desses habitats (LAURANCE et al., 2001).

Apesar da classe de fragmentos maiores que 1000 hectares possuir o menor percentual em relação ao total de fragmentos $(0,13 \%)$, essa classe possui a maior ocupação em área na paisagem (Tabela 4).

Tabela 4 - Número, área e percentagem dos fragmentos por classe de tamanho de fragmento de vegetação arbórea na paisagem da bacia hidrográfica do rio Marapanim

Table 4 - Patch number, area, and percentage by class size of arboreal vegetation in the landscape of Marapanim river watershed

\begin{tabular}{lccc}
\hline \multicolumn{1}{c}{ Classes } & Número de Fragmentos & Área dos fragmentos $($ ha $)$ & \% de ocupação \\
\hline$<\mathbf{5 0}$ ha & 6.716 & $15.294,86$ & 14,38 \\
$\mathbf{5 0}$ - $\mathbf{2 0 0}$ ha & 135 & 13.400 & 12,60 \\
$\mathbf{2 0 0}$ - $\mathbf{5 0 0}$ ha & 33 & 10.103 & 9,50 \\
$\mathbf{5 0 0}$ - $\mathbf{1 0 0 0}$ ha & 13 & $8.728,25$ & 8,21 \\
$>\mathbf{1 0 0 0}$ ha & 9 & $58.801,47$ & 55,30 \\
\hline Total & 6.906 & $106.327,06$ & 100,00 \\
\hline
\end{tabular}

Fonte: Autores (2019)

Observa-se que os maiores fragmentos da paisagem localizam-se principalmente na porção norte da bacia, no entorno do rio principal (Marapanim), caracterizado como área de preservação permanente do recurso hídrico. Esses fragmentos possuem a forma mais alongada, formando os corredores de Mata ciliar. As zonas ripárias exercem papel fundamental na manutenção da qualidade da água e da resiliência da microbacia hidrográfica, uma vez que influenciam na capacidade de armazenamento de água, estabilidade das margens, equilíbrio térmico e formação de corredores ecológicos (ATTANASIO et al., 2012). Além disso, a conectividade da mata ciliar 
propicia a diminuição do número de fragmentos florestais, tal como pode ser observado na bacia hidrográfica do rio Marapanim (Figura 3).

\section{Figura 3 - Classes de tamanho de fragmentos de vegetação arbórea da bacia hidrográfica do rio Marapanim-PA}

Figure 3 - Patch size classes of arboreal vegetation of Marapanim river watershed

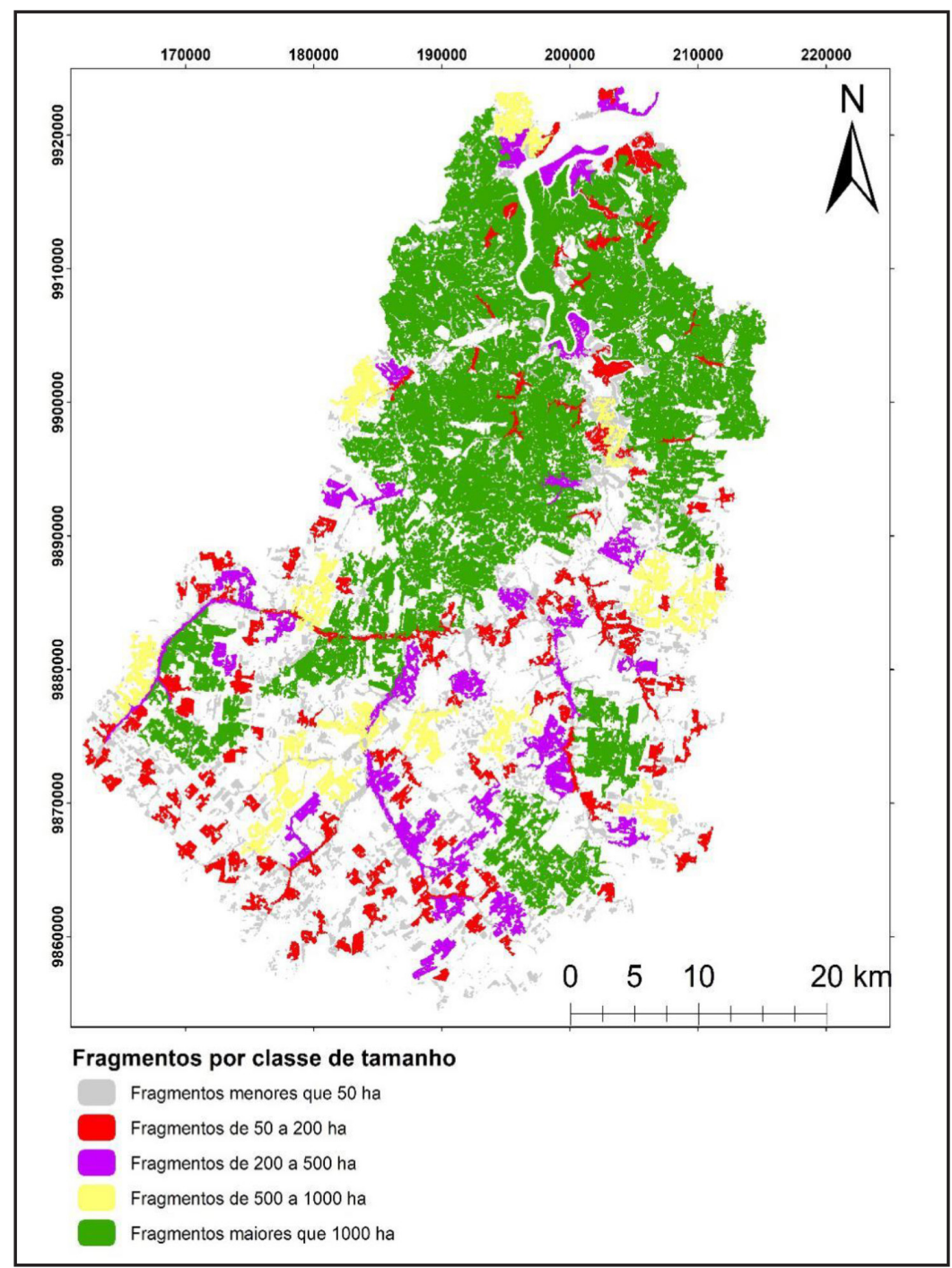

Fonte: Autores (2019)

Nota-se ainda a partir da Figura 3 que a maioria dos fragmentos se concentram na parte sul da bacia, sendo a porção norte relativamente mais preservada em termos de fragmentação. Essa área abarca municípios com menor densidade populacional: Terra alta, Marapanim e Magalhães Barata (Figura 1) e consequentemente com menor impacto ambiental associado às atividades antrópicas, já que o crescimento das atividades humanas associado às diferentes formas de uso e ocupação do espaço e exploração dos recursos naturais é o que impulsiona o processo de fragmentação florestal (TABARELLI et al., 2010). 


\section{Conclusão}

A área da bacia hidrog ráfica estudada é composta por 29,6\% de áreas de agricultura, sendo essa a principal atividade antrópica que mais alterou a paisagem na área de estudo. Ressalta-se o destaque para a agricultura de derruba-e-queima, comum em áreas do nordeste paraense.

O estudo da estrutura da paisagem mostrou que há predominância de fragmentos pequenos na paisagem da bacia, enfatizando o impacto das atividades humanas na área. Os fragmentos maiores, presentes principalmente no entorno do rio Marapanim, encontram-se relativamente bem preservados, formando os corredores de mata ciliar que protegem o recurso hídrico.

Oalto comprimento de borda mostra ocomprometimento na manutençãoda biodiversidade dos fragmentos de vegetação arbórea da bacia hidrográfica. A forma dos fragmentos é mais irregular, indicando a tendência de sofrerem maior influência das perturbações externas (efeito de borda).

Considerando o raio de busca de 100 metros, o valor zero do índice de proximidade médio demonstra a necessidade de implantação de corredores ecológicos que visem interligar fragmentos isolados, a fim de aumentar a proximidade e assim permitir maior movimentação da biota.

A conectividade dos fragmentos de vegetação arbórea foi considerada baixa, o que influencia negativamente no fluxo gênico das espécies que compõe a vegetação arbórea da bacia hidrográfica. Assim, ações de manejo devem ser priorizadas para melhoria da conectividade dos fragmentos e consequente diminuição do grau de isolamento.

Os resultados obtidos com este estudo podem ser utilizados para a definição de políticas de desenvolvimento visando a gestão sustentável dos recursos naturais. Isso inclui também a definição de estratégias para recuperação e preservação dos fragmentos remanescentes da vegetação arbórea nativa para, dessa forma, viabilizar a perpetuação das espécies, manutenção da biodiversidade e dos serviços ecossistêmicos.

\section{Referências}

ALMEIDA, C. G. Análise espacial dos fragmentos florestais na área do Parque Nacional dos Campos Gerais, Paraná. 2008. Dissertação (Mestrado em Geografia) - Universidade Estadual de Ponta Grossa, Ponta Grossa, 2008.

ALVARES, C. A. et al. Koppen's climate classification map for Brazil. Meteorologische Zeitschrift, Stuttgart, v. 22, n. 6, p. 711-728, 2014.

ARIMA, E. Y. et al. Spontaneous colonization and forest fragmentation in the Central Amazon Basin. Annals of the Association of America Geographers, [s. 1.], v. 103, n. 6, p. 1485-1501, 2013.

ATTANASIO, C. M. et al. A importância das áreas ripárias para a sustentabilidade hidrológica do uso da terra em microbacias hidrográficas. Bragantia, Campinas, v. 71, n. 4, p. 493-501, 2012.

AZEVEDO, D. G.; GOMES, R. L.; MORAES, M. E. B. Estudos da fragmentação da paisagem na definição de áreas prioritárias para a recuperação ambiental da bacia hidrográfica do rio Buranhém. Boletim de Geografia, Maringá, v. 34, n. 2, p. 127-144, 2016.

BENDER, D. J.; THISCHENDORF, L.; FAHRIG, L. Using patch isolation metrics to predict animal movement in binary landscapes. Landscape Ecology, Tempe, v. 18, p. 17-39, 2003. 
BERTRAND, G. Paisagem e geografia física global: esboço metodológico. RA'E GA, Paraná, n. 8, p. 141-152, 2004.

CABACINHA, C. D.; CASTRO, S. S.; GONÇALVES, D. A. Análise da estrutura da paisagem da alta bacia do rio Araguaia na savana brasileira. Floresta, Curitiba, v. 40, n. 4, p. 675-690, 2010.

CALEGARI, L. et al. Análise da dinâmica de fragmentos florestais no município de Carandaí, MG, para fins de restauração florestal. Revista Árvore, Viçosa, MG, v. 34, n. 5, p. 871-880, 2010.

CASIMIRO, P. C. Estrutura, composição e configuração da paisagem: conceitos e princípios para a sua quantificação no âmbito da ecologia da paisagem. Revista Portuguesa de Estudos regionais, Angra do Heroísmo, n. 20, p. 75-99, 2009.

CHAVEZ, P. S. An improved dark-object subtraction technique for atmospheric scattering correction of multispectral data. Remote Sensing of Environment, Amsterdã, v. 24, p. 459-479, 1988.

COELHO, V. et al. Dinâmica do uso e ocupação do solo em uma bacia hidrográfica do semiárido brasileiro. Revista Brasileira de Engenharia Agrícola e Ambiental, Campina Grande, v. 18, n. 1, p. 64-72, 2014.

CONGALTON, R. G. A review of assessing the accuracy of classifications of remotely sensed data. Remote Sensing of Environment, Amsterdam, v. 37, p. 35-46, 1991.

CORDEIRO, I. M.; RANGEL-VASCONCELOS, L. G.; SCHWARTZ, G. O manejo da floresta secundária na Amazônia oriental. In: CORDEIRO, I. M. et al. Nordeste Paraense: panorama geral e uso sustentável das florestas secundárias. Belém: EDUFRA, 2017. p. 163-190.

DIAS, G. F. M. et al. A relação entre as mudanças na paisagem e a vazão da bacia do rio Capim, Pará, Brasil. Boletim do Museu Paranaense Emílio Goeldi de Ciências Naturais, Belém, v. 14, n. 2, p. 255-270, maio/ago. 2019.

HENTZ, A. M. K. et al. Avaliação da fragmentação dos remanescentes florestais da Bacia Hidrográfica do Rio Iguaçu - PR, Brasil. Enciclopédia Biosfera, Goiânia, v. 11 n. 21, p. 28422858, 2015.

HOLANDA, A. C. et al. Estrutura de espécies arbóreas sob efeito de borda em um fragmento de floresta estacional semidecidual em Pernambuco. Revista Árvore, Viçosa, MG, v. 34, n. 1, p. 103-114, 2010.

JUVANHOL, R. S. et al. Análise Espacial de Fragmentos Florestais: caso dos Parques Estaduais de Forno Grande e Pedra Azul, Estado do Espírito Santo. Floresta e Ambiente, Rio de Janeiro, v. 18, n. 4 , p. 353-364, 2011.

LAURANCE, W. Hyper-Disturbed Parks: Edge Effects and the Ecology of Isolated rainforest Reserved in Tropical Australia. In: LAURANCE, W.; BIERREGAARD, R. O. (ed). Tropical forest remnants: ecology, management and conservation of fragmented communities. Chicago: The University of Chicago Press, 1997. p. 33-44.

LAURANCE, W. et al. The future of the Brazilian Amazon: development trends and deforestation. Science, Washington, v. 291, n. 5503, p. 438-439, 2001.

LAURANCE, W. et al. Rainforest fragmentation kills big trees. Nature, Londres, v. 404, p. 836, 2000.

MACHADO, W. P. et al. Identificação de padrões de vegetação e análise dos fragmentos florestais a partir do processamento digital de imagens e análise morfométrica em imagens ASTER no município de Cromínia-GO. Espaço e Geografia, Brasília, v. 15, n. 1, p. 229-263, 2012.

MCGARIGAL, K.; MARKS, B. J. FRAGSTATS: spatial pattern Analysis program for quantify in gland scape structure. Gen. Tech. Rep. PNW-GTR-351. Portland: U.S. Department of Agriculture, 
Forest Service, Pacific Northwest Research Station, 1995. 122 p.

MEDINA, G. F.; VIEIRA, M. V. Conectividade funcional e a importância da interação organismopaisagem. Oecologia Brasileira, Rio de Janeiro, v. 11, n. 4, p. 493-502, 2007.

METZGER, J. P. O que é ecologia de paisagens? Biota Neotropica, Campinas, v. 1, n. 1, p. 1-9, 2001.

NASCIMENTO, H.; LAURANCE, W. Efeitos de área e de borda sobre a estrutura florestal em fragmentos de floresta de terra-firme após 13-17 anos de isolamento. Acta Amazônica, Manaus, v. 36, n. 2, p. 183-192, 2006.

PEREIRA, J. L. V. et al. Métricas da paisagem na caracterização da evolução da ocupação da Amazônia. Geografia, Rio Claro, v. 26, n. 1, p. 59-90, 2001.

PIROVANI, D. B. et al. Análise espacial de fragmentos florestais na bacia do rio Itapemirim, ES. Revista Árvore, Viçosa, MG, v. 38, n. 2, p. 271-281, 2014.

REZENDE, R. A. Fragmentação da flora nativa como instrumento de análise da sustentabilidade ecológica de áreas protegidas - Espinhaço Sul (MG). 2011. Tese (Doutorado em Ciências Naturais) - Universidade Federal de Ouro Preto, Ouro Preto, 2011.

SOUZA, S. R. et al. Dinâmica da paisagem na bacia hidrográfica do Rio Apeú, nordeste do Pará, Brasil. Revista Acadêmica Ciência Agrária e Ambiental, Curitiba, v. 9, n. 2, p. 141-150, 2011.

TABARELLI, M. et al. Prospects for biodiversity conservation in the Atlantic Forest: Lessons from aging human-modified landscapes. Biological Conservation, Amsterdam, v. 143, p. 2328$2340,2010$.

VIDOLIN, G. P.; BIONDI, D.; WANDEMBRUCK, A. Análise da estrutura da paisagem de um remanescente de floresta com Araucária, Paraná, Brasil. Revista Árvore, Viçosa, MG, v. 35, n. 3, p. 515-525, 2011.

VIEIRA, I. C. G.; TOLEDO, P. M.; ALMEIDA, A. Análise das modificações da paisagem da região Bragantina, no Pará, integrando diferentes escalas de tempo. Ciência e Cultura, Campinas, v. 59 n. 3, p. 27-30, 2007. 